Article

\title{
Vertical Profiles of Wind-Blown Sand Flux over Fine Gravel Surfaces and Their Implications for Field Observation in Arid Regions
}

\author{
Jiaqi Liu *(D, Reiji Kimura and Jing Wu \\ Arid Land Research Center, Tottori University, Hamasaka 1390, Tottori 680-0001, Japan; \\ rkimura@tottori-u.ac.jp (R.K.); wu.jing@tottori-u.ac.jp (J.W.) \\ * Correspondence: ryuu731@tottori-u.ac.jp
}

Received: 10 August 2020; Accepted: 22 September 2020; Published: 24 September 2020

\begin{abstract}
We used a compact boundary layer wind tunnel equipped with a turbulence generator and a piezoelectric blown-sand meter to investigate the effects of the surface coverage of fine gravel on wind-blown sand flux. The vertical profile of wind-blown sand over a flat sand surface showed an exponential distribution at all wind speeds, whereas the profile over gravel surfaces of $20 \%$ or greater coverage showed a non-monotonic vertical distribution. At $20 \%$ to $30 \%$ gravel coverages, a peak of wind-blown sand flux developed between 6 and $10 \mathrm{~cm}$ above the ground at all wind speeds because of less energy loss due to grain-bed collisions at that level. To analyze the erosional state of wind-blown sand, we used the Wu-Ling index $(\lambda)$ of the mass-flux density of sand-bearing wind. Values of $\lambda$ for all gravel coverages were greater than 1 at all wind speeds, indicating an unsaturated (erosional) state. Moreover, we found that the wind-blown sand flux at $4 \mathrm{~cm}$ height accounted for about $20 \%$ of the total flux regardless of wind speed and gravel coverage. This finding can simplify future estimations of total near-surface wind-blown sand flux based on field observations because such measurements can be taken at just one height.
\end{abstract}

Keywords: arid regions; boundary layer wind tunnel; wind-blown sand flux; vertical profiles; fine gravel

\section{Introduction}

Desertification and dust storms are severe environmental and socio-economic concerns in many parts of the world, especially in arid and semi-arid regions (e.g., [1]). Dust storms are common in desertified and otherwise degraded land areas and can have local and regional effects on human and livestock health, air pollution, and soil erosion (e.g., [2,3]). The Gobi Desert of southern Mongolia is one of the main source regions of Asian dust. Land surfaces in the Gobi Desert are sensitive to both climate change and human activities, both of which contribute to frequent dust storms that cause progressive desertification [4]. Identification of dust-emitting areas in southern Mongolia will allow those areas to be targeted for mitigation of the damage caused by dust transport and desertification.

Effective countermeasures for dust transport require an understanding of the vertical profile of wind-blown sand flux. In particular, variations with height of sand flux determine the intensity of sand transport [5], which in turn reflects the saturation state of wind-blown sand and its effect on surface erosion [6]. Previous quantitative analyses of the structural characteristics of wind-blown sand (e.g., [7-9]) have concluded that $90 \%$ of wind-blown sand particles are transported in a near-surface layer within $31 \mathrm{~cm}$ of the ground surface. Similarly, Wu [9] also reported that $80 \%$ is within $10 \mathrm{~cm}$ of the surface. Results from wind tunnel experiments and field observations have also indicated that wind-blown sand transport is a near-surface phenomenon [5]. 
The structural characteristics of the vertical profile of wind-blown sand are affected by several factors, including wind speed, sand flux, and the nature of the underlying surface [10]. Most of the previous researchers mentioned above have investigated the vertical profile of wind-blown sand flux over sand surfaces, although some recent studies have considered different surfaces, especially those covered by great gravels in the Gobi Desert (e.g., [11]). For example, Zhang, et al. [12] used mobile wind tunnel experiments in the field to measure wind-blown sand over surfaces of graded gravel of $4 \mathrm{~cm}$ diameter and found that the gravel absorbed the momentum of wind-blown sand, thus protecting the underlying natural surface from wind erosion. Tan, et al. [13] compared the results of field observations and wind tunnel experiment on the Gobi surface with gravel heights ranging from 10 to $30 \mathrm{~mm}$, and concluded that graded gravel pavements can be used in the Gobi Desert to prevent wind-blown transport of sand in areas where vegetative countermeasures are limited by the dry environment. Lv and Dong [14] pointed out that the effects of various natural bed surfaces on the structural characteristics of wind-blown sand differ from those of artificial graded gravel surfaces. The natural surface in the Gobi region, including the Gobi Desert in southern Mongolia, is covered mainly by fine gravel, sand, and clay, of which the gravel coverage is $30 \%$ to $40 \%$ [15]. However, little is known about the effects of fine gravel or its coverage on the vertical profile of wind-blown sand.

Characteristics of blown-sand flux can be directly examined based on field observations; however, clarification of the mechanism is hampered by the uncontrollable wind speeds of the field environment. To conduct experiments on the vertical profile of wind-blown sand flux at controlled wind speeds, it is necessary to generate a simulated atmospheric boundary layer in a wind tunnel [16]. Moreover, the use of sand traps to measure blown-sand flux introduces uncertainties about the aerodynamics of wind-blown sand. For example, when sand traps of the same capacity are used, the length of time needed for a given volume of sand to collect will differ for different wind speeds [17].

In this study, we compared the vertical profiles of wind-blown sand flux over a flat sand surface with those over a flat fine gravel surface by using a recently developed compact wind tunnel $[18,19]$ equipped with a piezoelectric wind-blown sand meter. We also investigated the influence of different gravel coverages on the vertical profile of wind-blown sand.

\section{Experiments}

\subsection{Wind Tunnel and Piezoelectric Blown-Sand Meter}

To characterize the vertical profiles of wind-blown sand flux, we conducted experiments in a small-scale, open-circuit wind tunnel at the Arid Land Research Center (ALRC), Tottori University (Figure 1). The wind tunnel was $8.25 \mathrm{~m}$ long, had a cross section measuring $0.8 \mathrm{~m} \times 0.5 \mathrm{~m}$, and could generate air-flow speeds of up to $12 \mathrm{~m} \mathrm{~s}^{-1}$, controlled by adjustment of a power inverter. Wind speeds were measured with a Pitot tube at a height of $20 \mathrm{~cm}$ at the entrance of the observation space. A group of turbulence generators comprising spires and roughness blocks was installed between the blower and the sand bed $[18,19]$. The turbulence intensity at wind speed $8 \mathrm{~m} \mathrm{~s}^{-1}$ was 0.012 . The system of turbulence generators we used generated a thick boundary layer $(34 \mathrm{~cm}$ high) over the sand bed, a roughness length close to that of the natural field environment, and uniform distributions of horizontal and vertical wind speed over the observation space. Detailed information on the structure of the wind tunnel and the design of the turbulence generators is provided by Liu and Kimura [16]. 


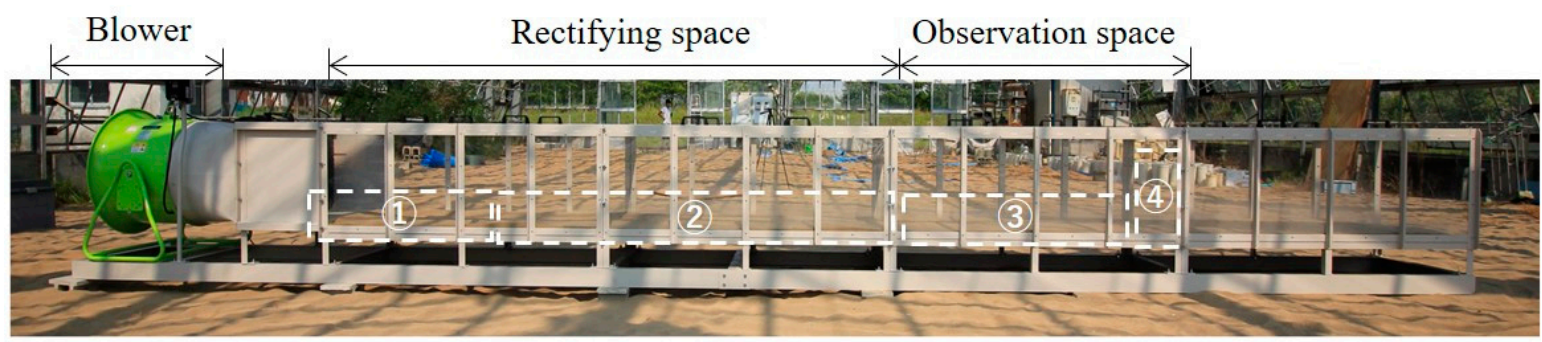

(1) Turbulence generators (Spires and Roughness blocks) (2) Sand bed (3) Gravel surface

(4) Piezoelectric blown-sand meter

Figure 1. Photograph of the wind tunnel used in this study.

We measured vertical profiles of wind speed without sand transportation along the centerline of the wind tunnel at $0.6 \mathrm{~m}$ intervals from the start of the observation space, all of which showed logarithmic distributions (Figure 2). We then obtained similar values of roughness length and wind shear velocity at the four measuring points. Because changes in shear velocity may affect the distance needed for blown-sand flux to approach an equilibrium value [20], our use of relatively uniform roughness length in the observation space minimized its effect on shear velocity. The roughness length we obtained in the wind tunnel was $0.003 \pm 0.0007 \mathrm{~cm}$, which is close to an observed value in the Taklimakan Desert $(0.004-0.005 \mathrm{~cm})$ [21].

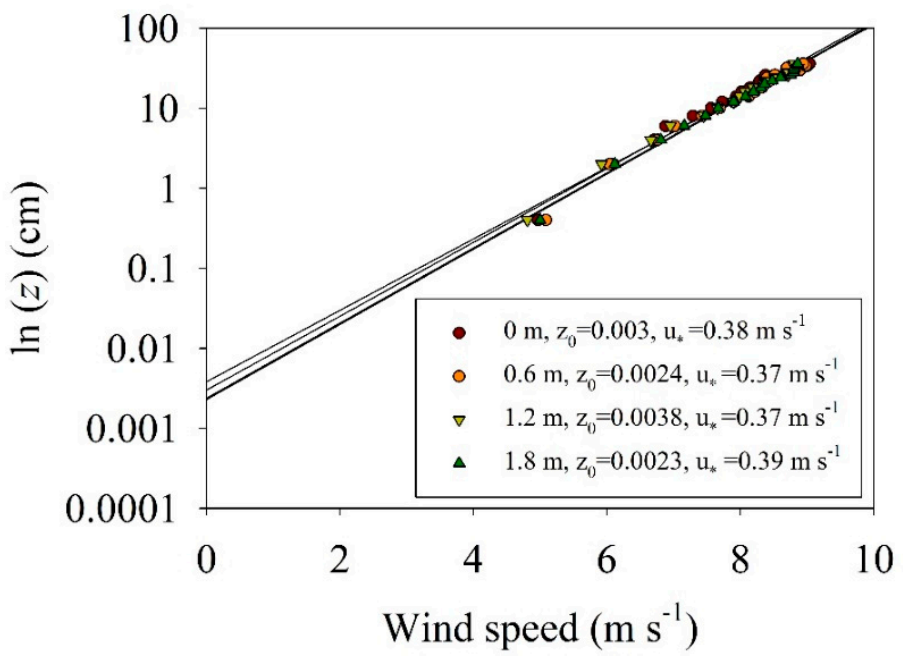

Figure 2. Roughness lengths $\left(\mathrm{z}_{0}\right)$ and wind shear velocity $\left(\mathrm{u}_{*}\right)$ derived from wind speed profiles at distances of $0,0.6,1.2$, and $1.8 \mathrm{~m}$ from the start of observation space at wind speed of $8 \mathrm{~m} \mathrm{~s}^{-1}$.

The instrument used to measure blown sand was the piezoelectric wind-blown sand meter used a piezoelectric transducer with high-precision ultrasonic sensors [22]. A cone-type resonator of $6.5 \mathrm{~mm}$ diameter mounted on the sensor portion of the piezoelectric transducer enabled highly accurate counting of blown sand grains; that is, each sand grain hitting the surface of the resonator generated a clear electrical signal from which the number of sand particles could be determined. The short response time of this signal, $0.001 \mathrm{~s}$ or less, further enhanced the high accuracy of grain counting [17] (Figure 3). 


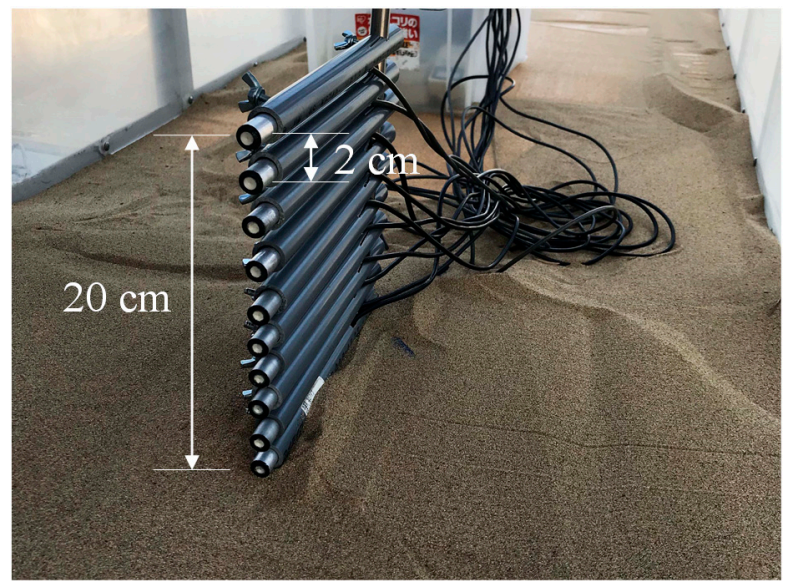

Figure 3. Photograph of the piezoelectric blown-sand meter used in this study.

\subsection{Measurement of Wind-Blown Sand Flux}

A layer of loose sand measuring $2.6 \mathrm{~m} \times 0.78 \mathrm{~m} \times 0.05 \mathrm{~m}$ was placed between the turbulence generators and the observation space to provide a sand source (Figure 1). The sand (median particle size $350 \mu \mathrm{m}$ ) was from the Tottori sand dunes [23]. The gravel (5 to $10 \mathrm{~mm}$ grain size) we used in the observation space was from the Tenryu River basin and was similar in size to the gravels of the Gobi Desert in southern Mongolia. Gravel coverage was controlled by bonding different amounts of gravel to wooden boards installed in the observation space. The gravel coverage was set at $5 \%$, $10 \%, 15 \%, 20 \%, 25 \%$, and $30 \%$ by bonding an appropriate amount of gravel to sand-covered wooden boards measuring $0.4 \mathrm{~m} \times 0.9 \mathrm{~m}$. After three trials, we found that an average of $3.24 \mathrm{~kg}$ of gravel was needed to provide $100 \%$ cover. For $30 \%$ gravel coverage, approximately that of the dust source region in southern Mongolia, we required $0.97 \mathrm{~kg}$ of gravel (Figure 4).

(a) Experimental gravel coverage: $30 \%$

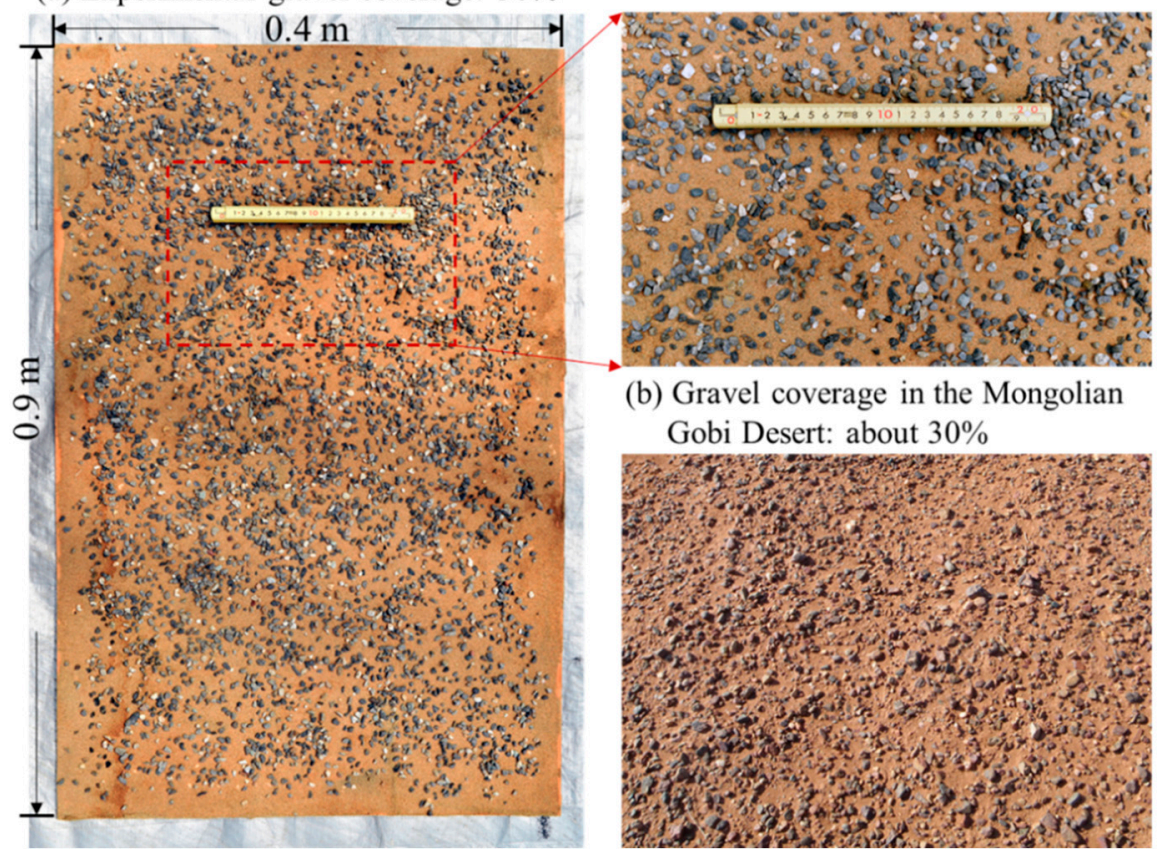

Figure 4. Photographs for comparison of gravel size and coverage of $30 \%$ (a) in our wind tunnel experiments and (b) in the Mongolian Gobi Desert.

Experiments were carried out at wind velocities of 7, 8, 9, and $10 \mathrm{~m} \mathrm{~s}^{-1}$ over a flat surface covered with Tottori sand and for six coverages of gravel surface $(5 \%, 10 \%, 15 \%, 20 \%, 25 \%$, and $30 \%)$. Sand flux 
was simultaneously recorded by a vertical array of ten piezoelectric blown-sand meters mounted at 2-cm intervals from 2 to $20 \mathrm{~cm}$ height above the surface at the midline of the downwind end of the observation space (Figure 3). To ensure that there was enough source sand under the maximum wind speed, in each group of experiments, the wind speed was held constant for 10 min during blown-sand flux acquisition. The recording interval was $1 \mathrm{~s}$.

The measured number of blown sand particles $n$ at each sensor was converted to blown sand flux $q_{\text {Trap }}\left(\mathrm{kg} \mathrm{m}^{-2} \mathrm{~s}^{-1}\right)$ according to the following equations of Udo [22]:

$$
q_{\text {Sensor }}=\frac{\frac{4}{3} \pi\left(\frac{d}{2}\right)^{3} \rho_{s}}{\pi\left(\frac{d_{P S}}{2}\right)^{2} t_{0}} n=\frac{2 \rho_{s} d^{3} n}{3 d_{P S}{ }^{2} t_{0}}
$$

and

$$
q_{\text {Trap }}=10.571 q_{\text {Sensor }}
$$

where $d$ is the median sand particle size $(350 \mu \mathrm{m}), \rho_{s}$ is the density of sand $\left(2.65 \times 103 \mathrm{~kg} \mathrm{~m}^{-3}\right), d_{P S}$ is the diameter of the sensor $(12 \mathrm{~mm})$, and $t_{0}$ is the measurement time $(1 \mathrm{~s})$. The blown-sand flux was the average of 1-s measurements over $10 \mathrm{~min}$.

We analyzed variations of wind-blown sand flux as a function of height rather than the magnitude of the flux. We therefore followed the method of Dong and Qian [6] who normalized measured mass fluxes by the total sand flux, converting them to dimensionless relative values by using the following transformation:

$$
q_{r}(z)=\frac{q_{\operatorname{Trap}}(z)}{Q}
$$

where $q_{r}(z)$ is the relative blown-sand flux, representing the proportion of the flux at height $\mathrm{z}$ divided by the total flux, $q_{\text {Trap }}(z)$ is the measured blown sand flux at height $z(\mathrm{~cm})$, and $Q\left(\mathrm{~kg} \mathrm{~m}^{-2} \mathrm{~s}^{-1}\right)$ is the total blown sand flux, which is the sum of the measured flux within $10 \mathrm{~cm}$ height. The maximum measurement height for our discussion of the structure of blown sand flux was $10 \mathrm{~cm}$.

\subsection{The Wu-Ling Index: Determining the Balance between Erosion and Deposition by Wind-Blown Sand}

The vertical profile of wind-blown sand flux reflects not only the characteristics of the movement of two-phase wind-sand flow but also erosional characteristics of wind-blown sand [5]. Wu and Ling [24] proposed an index $\lambda$ to quantify the mass-flux density of a sand-bearing wind, which they determined on the basis of the structure of blown-sand flux in the lowermost $10 \mathrm{~cm}$ of the wind profile as follows.

$$
\lambda=\frac{Q_{2-10}}{Q_{0-2}}
$$

Here, $\lambda$ is the Wu-Ling index, $Q_{2-10}$ is the blown-sand flux between 2 and $10 \mathrm{~cm}$ above the ground, and $Q_{0-2}$ is the blown-sand flux from the surface to $2 \mathrm{~cm}$ height. $\mathrm{Wu}$ and Ling related this index to the balance between deposition of sand and erosion of the ground surface as follows: when $\lambda$ is close to 1 , the amount of sand ejected from the surface nearly equals to the amount of deposited sand and the surface is in erosional equilibrium, with neither net erosion nor net deposition; when $\lambda$ is less than 1 (the saturated state), sand transport towards the ground surface rapidly increases the amount of sand in the near-surface layer and reduces the momentum of sand-bearing wind in the upper layer, thus providing conditions for sand accumulation, deposition is dominant; and when $\lambda$ is greater than 1 (the unsaturated state), wind-blown sand maintains a relatively high transport capacity, erosion is dominant [24]. The Wu-Ling index, also defined as the index of sand-flux structure, or a characteristic value of sand flux, has been used to examine the state of wind-sand stream transport on both sand and gravel surfaces (e.g., $[25,26])$ and to evaluate the effectiveness of measures for prevention of wind erosion damage, especially in the Dunhuang Mogao Grottoes, China (e.g., [27]). 


\section{Results and Discussion}

Although we measured blown-sand flux in the interval from 2 to $20 \mathrm{~cm}$ above the surface, we discuss here only the vertical distribution of relative blown-sand flux within $10 \mathrm{~cm}$ of the surface. We chose this interval firstly because it has been recognized that the dominant effect of fine gravel surfaces on blown-sand flux occurs within this layer, and there is marked vertical variation in blown-sand flux outside this height range (e.g., $[16,25,26])$. Secondly, erosion or deposition of wind-blown sand is determined by its near-surface structural characteristics, especially between heights of 0-6 cm [27]. Our discussion of the erosional characteristics of wind-blown sand (Section 3.4) is based on the $\mathrm{Wu}$-Ling index, which is determined by the vertical profile of relative blown-sand flux at heights less than $10 \mathrm{~cm}$.

\subsection{Vertical Profile of Blown-Sand Flux over a Flat Sand Surface}

Our wind tunnel experiments over a flat sand surface showed similar variations of relative blown-sand flux with height at wind speeds of 7, 8, 9, and $10 \mathrm{~m} \mathrm{~s}^{-1}$; for each wind speed, the flux decayed exponentially with increasing height (Figure 5). We identified significant correlations $\left(R^{2}>0.98\right)$ between relative blown-sand flux and height. However, there were notable differences in flux for wind speed changes at each height. Flux decreased with increasing wind speed at $2 \mathrm{~cm}$ height, was independent of wind speed at $4 \mathrm{~cm}$ height, and increased with increasing wind speed at $4-10 \mathrm{~cm}$ height. We suggest that the contrasting changes of flux with increasing wind speed at lower and upper levels reflect an increase in the number of sand particles transported to higher levels as wind speed increased. Dong and Qian [6] similarly demonstrated that the flux of sediment increases more rapidly in upper layers as wind speed increases and that vertical movements of smaller particles are more sensitive to changes in the vertical gradient of wind speed. We also found that for all wind speeds the relative blown-sand flux reached an equilibrium state at $4 \mathrm{~cm}$ height, where it accounted for a little more than $20 \%$ of the total flux below $10 \mathrm{~cm}$ (Figure 5). On the basis of field observations in the Buguli Desert of Xinjiang, Wu and Ling [24] noted a similar equilibrium point at 2-4 cm height, where the proportion of blown-sand flux was about $15 \%$ of the total flux.

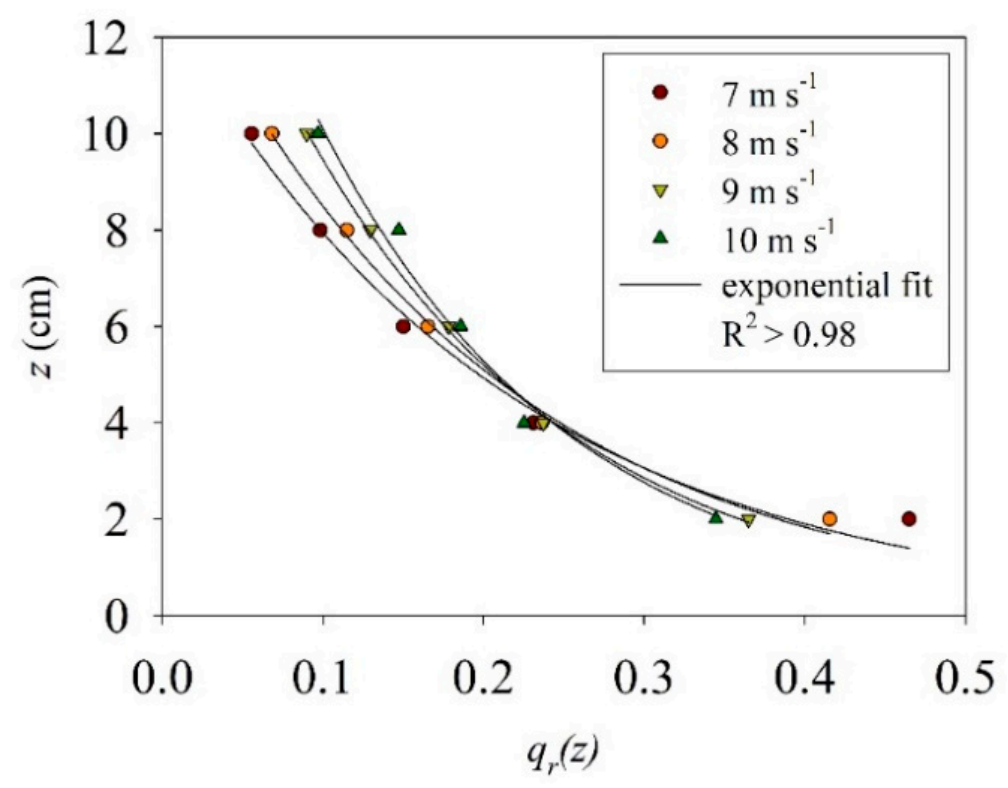

Figure 5. Vertical profiles of relative blown-sand flux $q_{r}(z)$ in Equation (3) on a flat sand surface at various wind speeds. 


\subsection{Vertical Profile of Blown-Sand Flux over Gravel Surfaces}

Vertical profiles of relative blown-sand flux over a surface with gravel coverage of 5\% (Figure 6a) showed similar vertical distributions of flux at wind speeds from 7 to $9 \mathrm{~m} \mathrm{~s}^{-1}$. When wind speed was increased to $10 \mathrm{~m} \mathrm{~s}^{-1}$, an equilibrium point appeared at $6 \mathrm{~cm}$ height, separating the near-ground vertical profile into two layers. The relative flux decreased abruptly in the lower layer and gradually increased in the upper layer. At gravel coverage of $10 \%$ (Figure $6 \mathrm{~b}$ ), the vertical profiles of relative flux were nearly the same for all wind speeds and the curves intersected at an equilibrium point at $6 \mathrm{~cm}$ height. The equilibrium point descended to $4 \mathrm{~cm}$ height when gravel coverage was increased to $15 \%$ (Figure 6c) and the vertical distributions of relative flux were similar at wind speeds of 8-10 $\mathrm{m} \mathrm{s}^{-1}$. Below $4 \mathrm{~cm}$ height, the fluxes at $8-10 \mathrm{~m} \mathrm{~s}^{-1}$ were greater than that at wind speed of $7 \mathrm{~m} \mathrm{~s}^{-1}$ but smaller than those above $4 \mathrm{~cm}$ height.
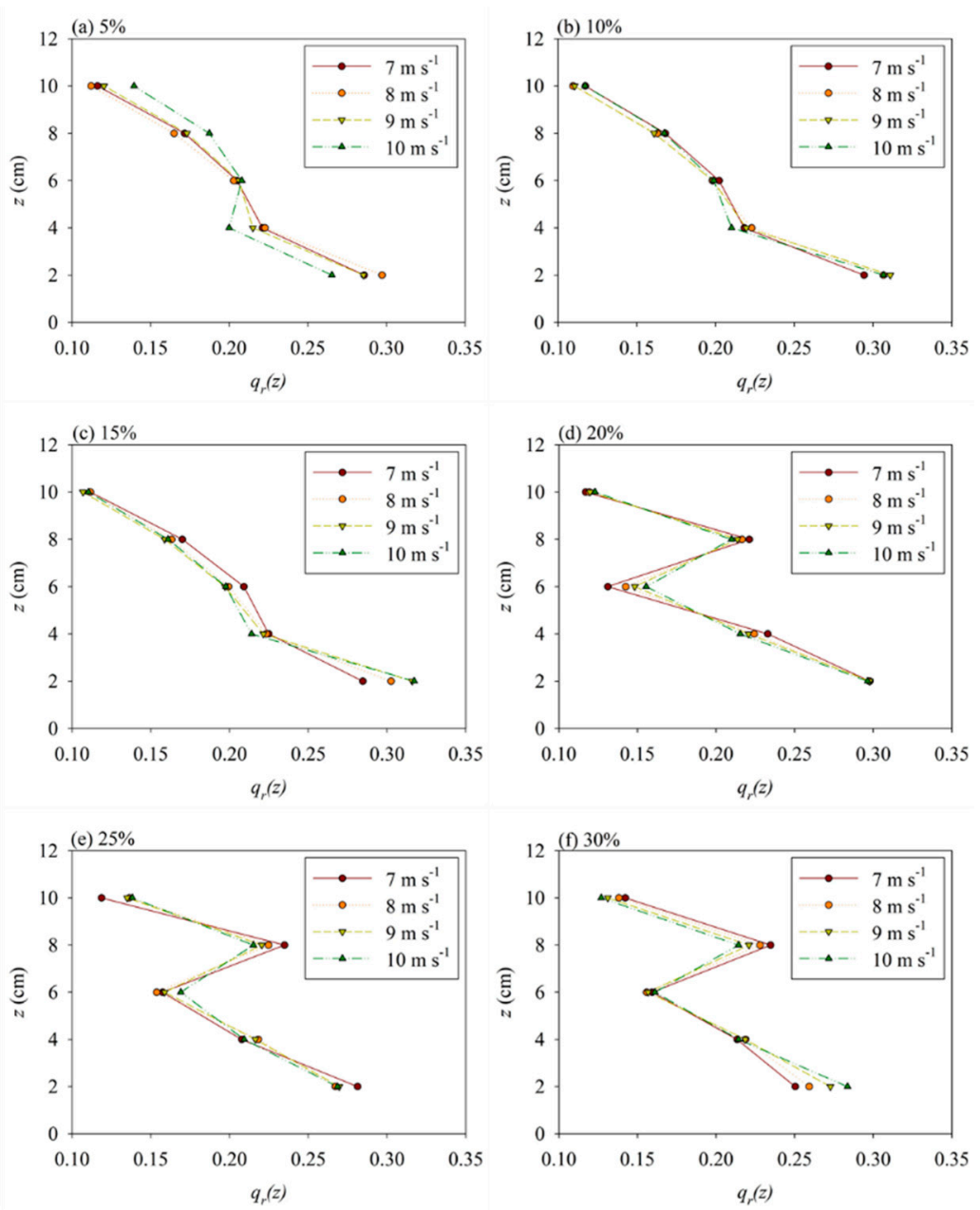

Figure 6. Comparison of vertical profiles of relative blown-sand flux $q_{r}(z)$ in Equation (3) for gravel coverages of (a) $5 \%$, (b) $10 \%$, (c) $15 \%$, (d) $20 \%$, (e) $25 \%$, and (f) $30 \%$ for the same wind speeds as in Figure 5.

At gravel coverages of $5 \%$ to $15 \%$ (Figure $6 a-c$ ), the relative flux of wind-blown sand maintained similar structural characteristics to that on the flat sand surface (Figure 5), exhibiting two distinct layers separated by an equilibrium point at $4 \mathrm{~cm}$ height. Our experiments showed that the equilibrium point in the relative flux profile was lowered by increasing the gravel coverage (Figure 6), thus increasing the proportion of sand particles moving at lower levels. Thus, the efficiency with which surface gravel trapped blown-sand at lower levels increased with increasing gravel coverage and peaked at $15 \%$ coverage, which is consistent with the results of Liu and Kimura [16]. Zhang, et al. [12] also observed 
an equilibrium point in the structure of sand flow over a Gobi surface with $60 \%$ gravel coverage, although their equilibrium point was at a height of $8 \mathrm{~cm}$. Above $8 \mathrm{~cm}$, they found that blown-sand flux increased with increasing wind speed. However, their vertical profile of sand flow differed from ours in that below the equilibrium point the relative flux peaked at $2 \mathrm{~cm}$ height, indicating upward increasing relative sand flux within the $0-2 \mathrm{~cm}$ layer. We attribute these differences to the coarser gravel $(2 \mathrm{~cm}$ grain size) they used in their experiments. Tan, et al. [28] reported that sand transport by wind can be reduced over gravel surfaces and that the degree to which it is reduced is related to gravel size.

At gravel coverages of $20 \%$ or more, the decreases of relative blown-sand flux with increasing height differed from those at $5 \%$ to $15 \%$ coverage. At about $6 \mathrm{~cm}$ height for gravel coverages $\geq 20 \%$ there was a marked increase of relative blown-sand flux with increasing height, which continued to about $8 \mathrm{~cm}$ height before reverting to a decreasing trend thereafter. There was a strong peak of more than $20 \%$ relative flux at $8 \mathrm{~cm}$ height (Figure $6 \mathrm{~d}$ ), comparable with the peak at $4 \mathrm{~cm}$ height for gravel coverages of $5 \%$ to $15 \%$ (Figure $6 a-c$ ). At gravel coverages of $20 \%$ and $25 \%$, the vertical profiles of relative blown-sand flux were similar for all experimental wind speeds, making it difficult to distinguish equilibrium points (Figure $6 \mathrm{~d}, \mathrm{e}$ ). For gravel coverage of $30 \%$, equilibrium was apparent between 4 and $6 \mathrm{~cm}$ height. As wind speed increased, the variations of the relative flux within the intervals of 2-4 and 6-10 cm height (Figure 6f) were the opposite of those on the flat sand surface (Figure 5).

The dramatic differences in the vertical profile of relative blown-sand flux that we identified between $15 \%$ and $20 \%$ gravel coverage have not been observed in previous studies. To test the accuracy of our experiments, we repeated our measurements after replacing the piezoelectric blown-sand meters and obtained similar vertical distributions of blown-sand flux, thus showing that our initial results were not a result of experimental error or the use of defective meters. We attribute the changes that we observed between 6 and $8 \mathrm{~cm}$ height to the direct effect of surface roughness on the vertical profile of blown-sand flux, thus reaffirming the finding of Zhang et al. [26] that surface roughness is dependent on gravel coverage. Liu and Kimura [16] investigated the aerodynamics of blown-sand transport over gravel surfaces and found that at gravel coverages of $20 \%$ or greater, the roughness length reverted to that of a flat sand surface. Their finding is in accordance with our present results.

\subsection{Vertical Structural Characteristics of Blown-Sand Flow}

Comparison at each wind speed of the vertical profiles of relative blown-sand flux over a flat sand surface and those over gravel surfaces of various coverages (Figure 7) showed distinctly different profiles in three layers above the ground surface. Below $4 \mathrm{~cm}$ height, the relative flux over the flat sand surface was greater than those of all of the gravel coverages at all wind speeds. This is because the fine gravel provided effective resistance to airflow at this level, thus reducing the energy carried by creeping sand particles. At heights of 4 to $6 \mathrm{~cm}$, the relative flux was highest for gravel coverages of $5 \%$ to $15 \%$ because of the effect of the gravel surface on saltation of the sand particles [29]. Compared with a flat sand surface, the lift-off velocity and angle of saltation of sand particles over a gravel surface are higher because of a more intensive grain-bed collision process [30,31]. Saltation on a gravel surface bounces the particles to a higher level, resulting in a larger proportion of relative flux above $4 \mathrm{~cm}$ height. Above $6 \mathrm{~cm}$, there were similar variations of relative flux for gravel coverages of $5 \%$ to $15 \%$ and $20 \%$ to $30 \%$. At gravel coverages of $20 \%$ or more, saltation of sand particles obtained more energy from airflow in the upper layer, forming distinct peaks at about $8 \mathrm{~cm}$ height.

More work is needed to clarify the effect of sand movement processes (saltation and creep) on the vertical distribution of blown-sand flux. Detailed observations are needed of grain size distributions at different heights above the gravel surface.

The vertical profiles of relative blown-sand flux over the gravel surfaces differed from those on the flat sand surface, but these differences decreased as wind speed increased. At all wind speeds, the relative flux at $4 \mathrm{~cm}$ height was independent of surface characteristics and accounted for about $20 \%$ of the total blown-sand flux within the layer from 0 to $10 \mathrm{~cm}$ height. This constant proportion of 
total blown-sand flux at $4 \mathrm{~cm}$ height has important implications for estimating total sand flux from field observations. It means that future estimations of total blown-sand flux on the basis of field observations can be based on measurements at just one height above the ground. Although the system of turbulence generators we used adjusted the boundary layer to achieve an equal roughness length equivalent to natural conditions, verification of other similarity criteria in the wind tunnel, as well as field observations, will be required to validate and extend our results before their practical application. These are subjects in need of further study.
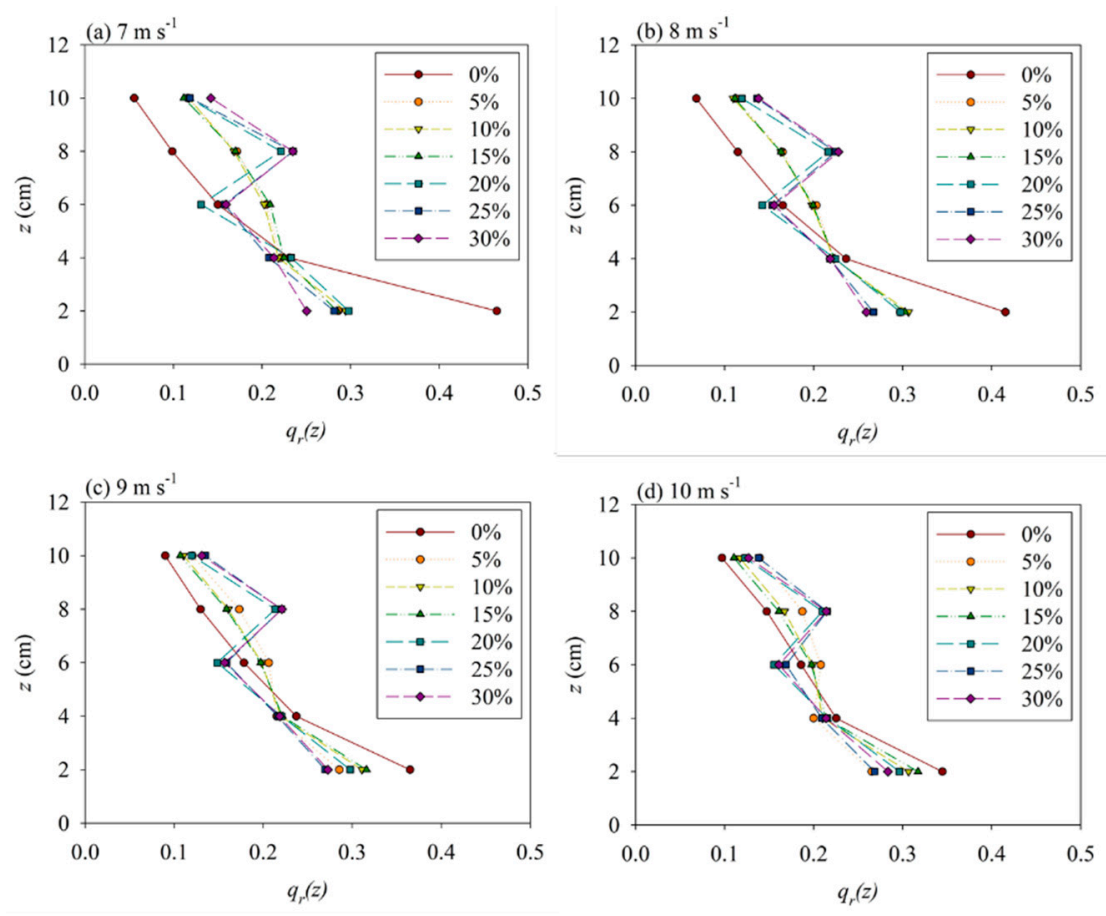

Figure 7. Comparison of vertical profiles of relative blown-sand flux $q_{r}(z)$ in Equation (3) for the same gravel coverages as in Figure 4 for the wind speeds of (a) 7, (b) 8, (c) 9, and (d) $10 \mathrm{~m} \mathrm{~s}^{-1}$ in Figure 3. A sand bed the same as that used in Figure 3 was used to represent the $0 \%$ gravel surface.

\subsection{Erosional Characteristics of Wind-Blown Sand}

Our calculations of the Wu-Ling index $\lambda$ (Table 1) for the flat sand surface (gravel coverage $0 \%$ ) were marginally greater than 1 for a wind speed of $7 \mathrm{~m} \mathrm{~s}^{-1}$, so the wind-blown sand was close to a saturated state and no significant amounts of erosion or deposition would occur. For a wind speed of $10 \mathrm{~m} \mathrm{~s}^{-1}, \lambda$ was considerably greater than 1 (an unsaturated state), indicating that the wind-blown sand would erode the ground surface. For our experiments over gravel surfaces, $\lambda$ was greater than 1 ( 2.15 to 2.99 ) for all wind speeds and all gravel coverages. These outcomes indicate that the wind-blown sand maintained an unsaturated state and the ground surfaces would be eroded for all the coverages of fine gravel we tested. This finding differs from those of previous studies that have examined the effects of great gravels on wind erosion. The main reason that great gravels can prevent erosion is because they reduce near-surface shear stress and increase the threshold velocity for sediment entrainment, thereby reducing the likelihood of wind-blown sediment transport [13].

Although the vertical profile of relative blown-sand flux is dependent on gravel coverage, and we found that optimal sand-trapping efficiency below $2 \mathrm{~cm}$ height occurred at $15 \%$ gravel coverage, the relative blown-sand flux does not control the balance between erosion and deposition by wind-blown sand over a fine gravel surface. Observations by Qu et al. [25] of different sand fluxes over different ground surfaces at Dunhuang Mogao Grottoes in the Gobi Desert returned $\lambda$ values of 0.87 and 1.47 for shifting sand and flat sand, respectively, and of 1.48 and 1.54 for gravel gobi and grit gobi, respectively. The average $\lambda(1.55)$ that we obtained at $0 \%$ gravel coverage (Table 1) was close to that obtained by 
$\mathrm{Qu}$ et al. [25]. The $\lambda$ values for a gravel surface in their observations were slightly lower than ours, but were still greater than 1 , reflecting the sand-transporting capability of an area extending from flat sand ground to a gravel surface at Mogao Grottoes. Their results for the unsaturated erosional state of wind-blown sand are consistent with those we have presented here.

Although the Wu-Ling index has already been adopted to clarify its relationship with the erosional characteristics of wind-blown sand, influencing factors for the development of sand transport processes and $\lambda$ values are complicated. $\lambda$ can only be used for qualitative identification of the status and tendency for the development of wind-sand stream transport [5].

Table 1. Relationship of the $\mathrm{Wu}-$ Ling index $(\lambda)$ to wind speed and gravel coverage for wind-blown sand in our experiments.

\begin{tabular}{cccccccc}
\hline \multirow{2}{*}{ Wind Speed $\left(\mathbf{m ~ s}^{-\mathbf{1}}\right)$} & \multicolumn{7}{c}{ Gravel Coverage (\%) } \\
\cline { 2 - 8 } & $\mathbf{0}$ & $\mathbf{5}$ & $\mathbf{1 0}$ & $\mathbf{1 5}$ & $\mathbf{2 0}$ & $\mathbf{2 5}$ & $\mathbf{3 0}$ \\
\hline 7 & 1.15 & 2.50 & 2.40 & 2.51 & 2.36 & 2.56 & 2.99 \\
8 & 1.41 & 2.37 & 2.26 & 2.31 & 2.36 & 2.74 & 2.86 \\
9 & 1.74 & 2.50 & 2.22 & 2.17 & 2.36 & 2.71 & 2.67 \\
10 & 1.90 & 2.77 & 2.26 & 2.15 & 2.37 & 2.73 & 2.53 \\
\hline Average & 1.55 & 2.54 & 2.29 & 2.29 & 2.36 & 2.69 & 2.76 \\
STDEV & 0.29 & 0.15 & 0.07 & 0.14 & 0.0004 & 0.07 & 0.18 \\
\hline
\end{tabular}

\section{Conclusions}

We examined the effects of various surface coverages (5\% to $30 \%$ ) of fine gravel on the vertical profile of relative wind-blown sand flux at wind speeds from 7 to $10 \mathrm{~m} \mathrm{~s}^{-1}$ and compared them to the profiles over a flat sand surface at the same wind speeds. Our findings are as follows.

1. On the flat sand surface, the vertical profiles of relative blown-sand flux showed an exponential distribution at all wind speeds. As wind speed increased, the proportion of blown-sand flux decreased below and increased above an equilibrium point $4 \mathrm{~cm}$ above the ground.

2. For each of the gravel coverages in our experiments, the vertical distributions of relative blown-sand flux were similar at all wind speeds, but they differed for the various gravel coverages. At coverages of $15 \%$ and lower, the profiles were similar to that of the flat sand surface, but their distributions were not exponential. At gravel coverages of $20 \%$ to $30 \%$, a peak of relative flux developed 6-10 $\mathrm{cm}$ above the surface because less energy was lost in grain-bed collision processes at that level.

3. The proportion of the relative blown-sand flux at $4 \mathrm{~cm}$ height was about $20 \%$ over the flat sand surface and over all of the gravel surfaces; thus, at that height, it was independent of both wind speed and gravel coverage.

4. The $\mathrm{Wu}$-Ling index $\lambda$ was greater than 1 for all gravel coverages at all experimental wind speeds, thus indicating an unsaturated (erosional) state of wind-blown sand in all experiments over a gravel surface.

Our results provide additional information about the vertical profile of wind-blown sand over fine gravel surfaces. In the Gobi Desert, although creeping sand particles can be trapped by surface gravel, wind-blown sand erosion will still occur due to the intensity of transport of sand particles by saltation. In addition, our finding of the lack of dependence at $4 \mathrm{~cm}$ height of blown-sand flux on either gravel coverage or wind speed indicated that future estimations of total blown-sand flux on the basis of field observations can be based on measurements at just one height above the ground surface.

Although our finding is a noteworthy contribution to research on near-surface wind-blown flux in the Gobi Desert, field observations will be required to validate and extend our results before their practical application. Firstly, in addition to the well-reproduced boundary layer and wind profiles 
in our experiments, other dynamic similarity criteria should be taken into consideration in the wind tunnel setup. Secondly, it is difficult to observe the evolution and equilibration of wind-blown sand in most of the past wind-tunnel experiments due to the insufficient length of the wind tunnel that did not meet the criteria for the saturated sand flux. This limitation indicates that the results obtained from our short wind tunnel are probably only valid for a specific stage of the development process of sand transport. Quantitative studies are required to determine the length needed for sand flux to reach the true equilibrium state. These are subjects in need of further study.

Author Contributions: Conceptualization, J.L. and R.K.; methodology, J.L. and J.W.; experiment and investigation, J.L.; Funding acquisition, R.K.; writing-original draft preparation, J.L. and J.W.; writing-review and editing, R.K. All authors have read and agreed to the published version of the manuscript.

Funding: This research was funded by Japan Society for the Promotion of Science KAKENHI, grant number $19 H 04239$.

Acknowledgments: We appreciate invaluable comments by two reviewers and editors on this paper.

Conflicts of Interest: The authors declare no conflict of interest.

\section{References}

1. Wang, T.; Zhu, Z. Study on sandy desertification in China-1. Definition of sandy desertification and its connotation. J. Desert Res. 2003, 23, 209-214.

2. Middleton, N.J. Desert dust hazards: A global review. Aeolian Res. 2017, 24, 53-63. [CrossRef]

3. Wang, X.; Huang, J.P.; Ji, M.X.; Higuchi, K. Variability of East Asia dust events and their long-term trend. Atmos. Environ. 2008, 42, 3156-3165. [CrossRef]

4. Kimura, R. Validation and application of the monitoring method for degraded land-area-based on a dust erodibility in eastern Asia. Int. J. Remote Sens. 2017, 38, 4553-4564. [CrossRef]

5. Wu, Z. Geomorphology of Wind-Drift Sands and Their Controlled Engineering; Science Press: Beijing, China, 2003.

6. Dong, Z.B.; Qian, G.Q. Characterizing the height profile of the flux of wind-eroded sediment. Environ. Geol. 2007, 51, 835-845. [CrossRef]

7. Chepil, W.S. Dynamics of wind erosion: I. Nature of movement of soil by wind. Soil. Sci. 1945, 60, 305-320. [CrossRef]

8. Sharp, R.P. Wind-Driven Sand in Coachella Valley, California-Further Data. Geol. Soc. Am. Bull. 1980, 91, 724-730. [CrossRef]

9. Wu, Z. Aeolian Geomorphology; Science Press: Beijing, China, 1987.

10. Znamensky, A.I. Experimental Research of Wind Erosion on Sands and Questions of Protection against Sand Drifts; Science Press: Beijing, China, 1960.

11. Liu, B.L.; Zhang, W.M.; Qu, J.J.; Zhang, K.C.; Han, Q.J. Controlling windblown sand problems by an artificial gravel surface: A case study over the gobi surface of the Mogao Grottoes. Geomorphology 2011, 134, 461-469. [CrossRef]

12. Zhang, W.M.; Tan, L.H.; Zhang, G.B.; Qiu, F.; Zhan, H.T. Aeolian processes over gravel beds: Field wind tunnel simulation and its application atop the Mogao Grottoes, China. Aeolian Res. 2014, 15, 335-344. [CrossRef]

13. Tan, L.H.; Zhang, W.M.; Qu, J.J.; Wang, J.Z.; An, Z.S.; Li, F. Aeolian sediment transport over gobi: Field studies atop the Mogao Grottoes, China. Aeolian Res. 2016, 21, 53-60. [CrossRef]

14. Lv, P.; Dong, Z.B. The status of research on the development and characteristics of mass-flux-density profiles above wind-eroded sediments: A literature review. Environ. Earth Sci 2014, 71, 5183-5194. [CrossRef]

15. Wang, X.; Lang, L.; Hua, T.; Wang, H.; Zhang, C.; Wang, Z. Characteristics of the Gobi desert and their significance for dust emissions in the Ala Shan Plateau (Central Asia): An experimental study. J. Arid Environ. 2012, 81, 35-46. [CrossRef]

16. Liu, J.Q.; Kimura, R. Wind speed characteristics and blown sand flux over a gravel surface in a compact wind tunnel. Aeolian Res. 2018, 35, 39-46. [CrossRef]

17. Hotta, S.; Horikawa, K. Vertical distribution of sand transport rate by wind. Coast. Eng. Jpn. 1993, 36, 91-110. [CrossRef] 
18. Liu, J.Q.; Kimura, R. Study on the boundary layer formation of a small simple type wind tunnel. Sand Dune Res. 2017, 63, 113-119.

19. Liu, J.Q.; Kimura, R. Development of a method to make a boundary layer with roughness length close to natural conditions in a simple wind tunnel. Sand Dune Res. 2017, 64, 1-8.

20. Andreotti, B.; Claudin, P.; Pouliquen, O. Measurements of the aeolian sand transport saturation length. Geomorphology 2010, 123, 343-348. [CrossRef]

21. Shao, Y.; Mikami, M. Heterogeneous saltation: Theory, observation and comparison. Bound. Layer Meteorol. 2005, 115, 359-379. [CrossRef]

22. Udo, K. Field Observations of Aeolian Sand Transport Rate Using a Piezoelectric Ceramic Sensor. Proc. Coast. Eng. JSCE 2008, 551-555. [CrossRef]

23. Abulitipu, A.; Kimura, R. Characteristics of the sand drifting of Tottori sand dune in springtime. Sand Dune Res. 2011, 58, 31-39.

24. Wu, Z.; Ling, Y.Q. A preliminary study of wind-blown sand movement and sand disaster prevention. Res. Sand Disaster Prev. 1965, 7, 14.

25. Qu, J.; Dong, G.; Wen, Z.; Zhang, W.; Hu, S. Sand drift encroachment in the Dunhuang Mogao Grottoes District and its control. Sci. China Ser. Earth Sci. 1997, 40, 197-206. [CrossRef]

26. Zhang, W.; Wang, T.; Wang, W.; Qu, J.; Xue, X.; Yao, Z. The gobi sand stream and its control over the top surface of the Mogao Grottoes, China. Bull. Eng. Geol. Environ. 2004, 63, 261-269. [CrossRef]

27. Zhang, W.M.; Wang, T.; Wang, W.F.; Liu, B.L. Wind tunnel experiments on vertical distribution of wind-blown sand flux and change of the quantity of sand erosion and deposition above gravel beds under different sand supplies. Environ. Earth Sci. 2011, 64, 1031-1038. [CrossRef]

28. Tan, L.H.; Zhang, W.M.; Qu, J.J.; Zhang, K.C.; An, Z.S.; Wang, X. Aeolian sand transport over gobi with different gravel coverages under limited sand supply: A mobile wind tunnel investigation. Aeolian Res. 2013, 11, 67-74. [CrossRef]

29. Pye, K.; Tsoar, H. Aeolian Sand and Sand Dunes; Springer Science \& Business Media: Berlin/Heidelberg, Germany, 2009; Volume XVI, p. 458. [CrossRef]

30. Kang, L.Q.; Guo, L.J.; Liu, D.Y. Reconstructing the vertical distribution of the aeolian saltation mass flux based on the probability distribution of lift-off velocity. Geomorphology 2008, 96, 1-15. [CrossRef]

31. Tan, L.H.; An, Z.S.; Zhang, K.; Qu, J.J.; Han, Q.J.; Wang, J.Z. Intermittent Aeolian Saltation Over a Gobi Surface: Threshold, Saltation Layer Height, and High-Frequency Variability. J. Geophys. Res. Earth 2020, 125, e2019JF005329. [CrossRef] 